\title{
BANDWIDTH ENHANCEMENT \& ANALYSIS OF MICROSTRIP ANTENNA WITH DGS FOR S AND X BAND APPLICATIONS
}

\author{
Kanchan Wagh and S. S. Shriramwar \\ ${ }^{1}$ Electronics Engineering, R.T.M.Nagpur University, Nagpur, India \\ kanchanwagh5@gmail.com,sshriramwar2@gmail.com
}

Abstract- Wideband antennas with dual band characteristics are mostly preferred in antenna communication. This letter presents a novel design of Microstrip patch antenna with dual band characteristic. The proposed design reports a dual band response with resonating frequencies of $5.8 \mathrm{GHz}$ and $9.3 \mathrm{GHz}$ having remarkable bandwidth about $1100 \mathrm{MHz}$ and $1430 \mathrm{MHz}$ respectively. It has been observed that $3 \mathrm{~dB}$ bandwidth intensifies after incorporating Defective Ground Structure and notches into the patch. This antenna covers both $S$ band $\& \mathrm{X}$ band. The return loss observed for this antenna is $-32.7 \mathrm{~dB}$ at $5.8 \mathrm{GHz}$ and $-25.03 \mathrm{~dB}$ at 9.3 GHz. VSWR has been investigated and found to be 1. CST Microswave studio software is used for the designed and simulation of $E$ Shape patch antenna with and without parasitic patches. This antenna can be used in Radar system at $S$ and $X$ band. The antenna simultaneously operates at two distinct bands.

Keywords - Parasitic patches, slots, DGS, RADAR, CST

\section{INTRODUCTION}

In recent scenario microstrip antennas are the popular antennas in the field of telecommunication [1]. Research has been perpetrated in the recent past to enhance the performance \& efficiency of these antennas. Due to extensive development in late 90's, the idea of using Microstrip array antenna in wireless communication was well established. Advantages of Microstrip antennas are reduced size, light weight, phase steering ability, ease of installation, low cost and these make the antenna the best choice of researchers \& manufacturers [2]. As discussed in [3] conventionally the radiation pattern is wide $\&$ hence proportionately the directivity is moderate. This typical problem can be control by expanding the element size. In this manner the directivity can be increased. But this is not the proper solution.

The technique to expand the antenna instead of changing the area or size of the discrete elements is very popular now a days. In this the radiating component or elements are assemble in a geometrical fashion and it is popular by the name of an array. Microstrip Antennas are widely used in radar and airborne application due to its various leading characteristics light weight, low cost and low profile. These antennas are easy to manufacture using printed technology. Wideband antennas are preferred in many applications. Mostly ultra wideband antennas are commonly designed and preferred for wideband application. In this paper our focused is on the improvement of bandwidth of an antenna with the help of DGS. Recently DGS plays crucial role in the field of Microstrip patch antenna design. This paper has used DGS structure for the enhancement of bandwidth. It is very crucial to increase bandwidth of an antenna. By using DGS

Received: May 9, 2019

Reviewed: August 20, 2019

Accepted: August 27, 2019

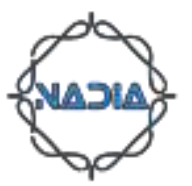


properly into the design, bandwidth improves surprisingly. The antenna will be designed for $\mathrm{S}$ and $\mathrm{X}$ band and also analysed in terms of return loss, gain, directivity and bandwidth. In the proposed design along with DGS we have incorporated slits into the design. The antenna bandwidth is improved by DGS and slits into the design. Partial ground plane along with slots into the ground plane also improves the bandwidth of an antenna. In our second design we have inserted asymetric slots into the partial ground plane.

\section{LITERATURE SURVEY}

In [1] author has proposed a design of $\mathrm{L}$ shaped hexagonal microstrip patch antenna. This antenna resonates at $4.94 \mathrm{GHz}$ and $8.02 \mathrm{GHz}$ with bandwidth of $100 \mathrm{MHz}$ and 400 $\mathrm{MHz}$ respectively. Antenna have been designed at three different bands like S,C and X bands for wireless communication application in [2]. The bandwidth they got for this antenna is $0.47 \mathrm{GHz}, 0.605 \mathrm{GHz}, 0.64 \mathrm{GHz}$ and $0.58 \mathrm{GHz}$ for $2.92 \mathrm{GHz}, 5.64 \mathrm{GHz}, 8.21$ $\mathrm{GHz}$ and $10.53 \mathrm{GHz}$ respectively. Author has designed a circular patch antenna and 8 elements array antenna in [3] for S band application. It is found that the bandwidth of the antenna array is $166 \mathrm{MHz}$. Rogers RT/Duroid substrate have been used for the antenna manufacturing process, size reduction upto $48 \%$ have also been achieved in [4] but the antenna has lower bandwidth. A reconfigurable antenna have been designed in [5]. The back radiations of the antenna is high. In our design the back lobe is less as compared to [5]. Dual band antenna have been designed in [6] and resonates at $4.1 \mathrm{GHz}$ and $9,5 \mathrm{GHz}$. But the bandwidth is very narrow. Broadband compact antenna is designed in [7] with bandwidth of $1.1 \mathrm{GHz}$ for both $\mathrm{S}$ band and $\mathrm{C}$ band. The antenna have been designed with inverted $\mathrm{U}$ slot and meander slot in ground plane. Inset feed antenna is designed simulated for wireless communication having less bandwidth [8]. Microstrip antenna array have been designed and explained in $[9,10]$. Sterred microstrip Phased array antenna have been demonstrated in [11] for higher gain. Microstrip antenna array have been discussed and designed in [15-18]. Compact size sierpinski fractal antenna has been proposed and presented in $[19,20]$. In our research work we have proposed a novel dual band antenna with and without parasitic patches. This frequency is used in radar system. The proposed antenna is suitable for radar application. For further gain enhancement and beam steering, array of an antenna can be designed. In our first design we have implemented the antenna using circular slots and slits. Partial ground plane also preferred for the enhancement of bandwidth. In our second proposed design we have incorporated three parasitic patches around the design along with partial ground and slots into the ground plane. In Section III, antenna design methodology have been discussed. In Section IV, microstrip antenna design and simulation results have been discussed. Gain and bandwidth enhancement techniques have been also discussed in this paper. We have got $400 \mathrm{MHz}$ and $300 \mathrm{MHz}$ bandwidth for E shape antenna without parasitic patches. It have been observed that hte bandwidth is drastically improved after the inclusion of parasitic patches and slots into the design. We have got $1100 \mathrm{MHz}$ and $1430 \mathrm{MHz}$ bandwidth at $5.8 \mathrm{GHz}$ and $9.6 \mathrm{GHz}$. Good impedance matching is achieved in this paper.

\section{ANTENNA DESIGN METHODOLOGY}

The aim of this paper is to design and simulate a wide bandwidth dual band Microstrip Patch antenna for S and X band. This antenna is the best suited reference antenna for radar system. Radar system requires radio signal for the detection of target. For generating radio signal it requires of an antenna. Air surveillance radar works under S band. Missile control, weather radar and marine radar works under X band. It has been observed that DGS results are better as compared with partial ground plane. DGS influences the bandwidth of an antenna immensely. This paper compares two antenna designs with partial ground plane and DGS. E Shape 
Microstrip Patch antenna has been designed and simulated. Initially we have designed a single antenna, then slits and circular ring slots have been inserted into the design. It has been observed that antenna parameters will get improved by inclusion of slits and circular rings into the design. The antenna comprises E shape after the inclusion of slits into the design. Then in the same design we have included parasitic patches to improve further bandwidth of an antenna. Also the ground plane slots have been altered for the betterment of results.

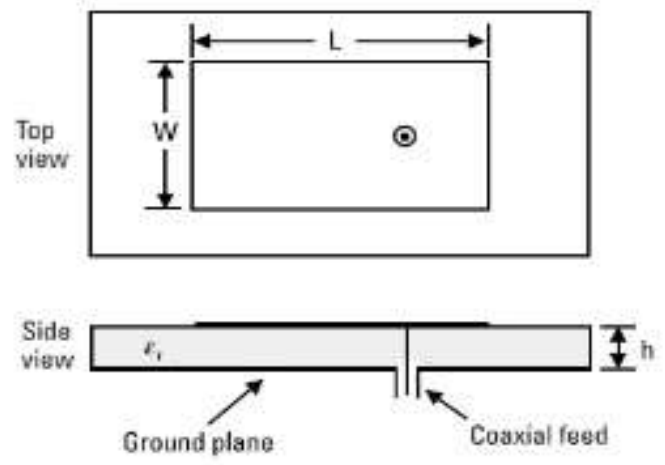

Fig. 1 Microstrip Antenna Configuration[6]

\section{ANTENNA DESIGN \& SIMULATION RESULTS}

Figure 1 shows traditional microstrip antenna designed at $2.4 \mathrm{GHz}$. This antenna is used for $\mathrm{C}$ band applications. Figure 2 exhibits the traditional microstrip patch antenna design at $2.4 \mathrm{GHz}$. Figure 3 shows return loss, VSWR and radiation pattern shows in Figures 4 and 5. Figure 6 shows 2 D radiation pattern and Figure 7 shows the E Shape Microstrip Patch Antenna for S Band \& X Band Radar System and from Figure 8 to Figure 13 depicts the simulated results of an antenna. Figure 14 shows the E Shape Microstrip Antenna with Parasitic Patches around it. Results of conventional antenna are moderate but after incorporating slots into the patch and DGS the results are improved. Bandwidth is dramatically increased after adding parasitic patches into the design along with DGS. The proposed antenna attains a good Bandwidth. This Antenna have been designed for $5.8 \mathrm{GHz}$ and $9.3 \mathrm{GHz}$ which covers $\mathrm{S}$ and $\mathrm{X}$ band. So the proposed antenna is mostly suitable for radar System.

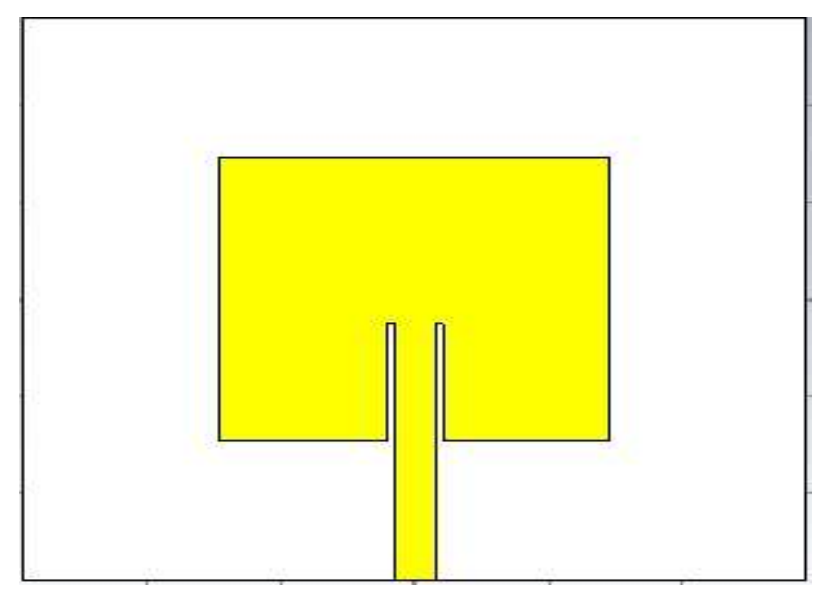

Fig. 2 Conventional M.P.A. for $2.4 \mathrm{GHz}$ 


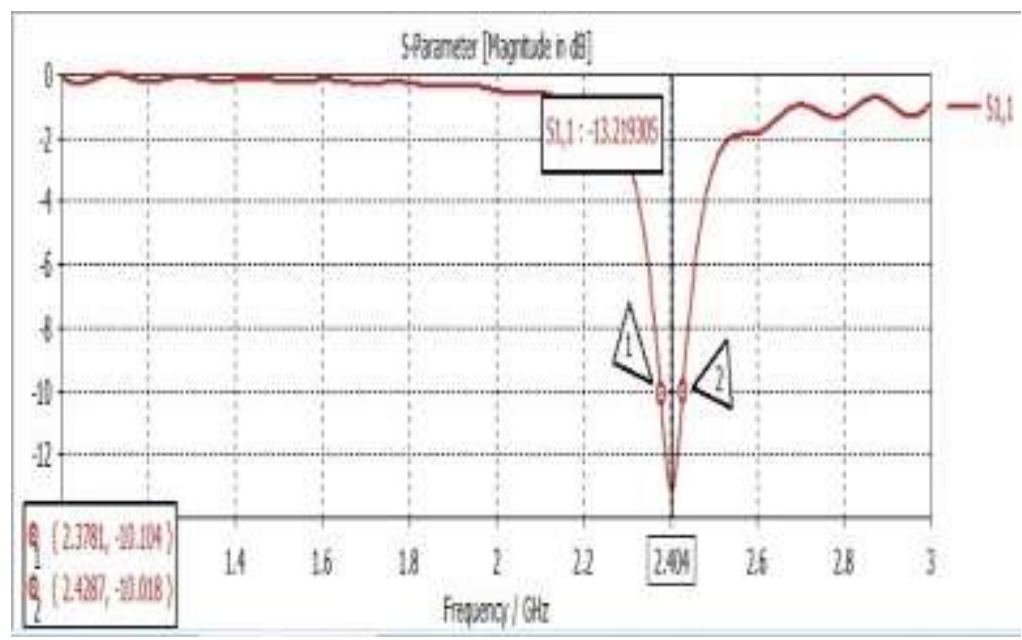

Fig. 3 R.L. of Conventional M.P.A.

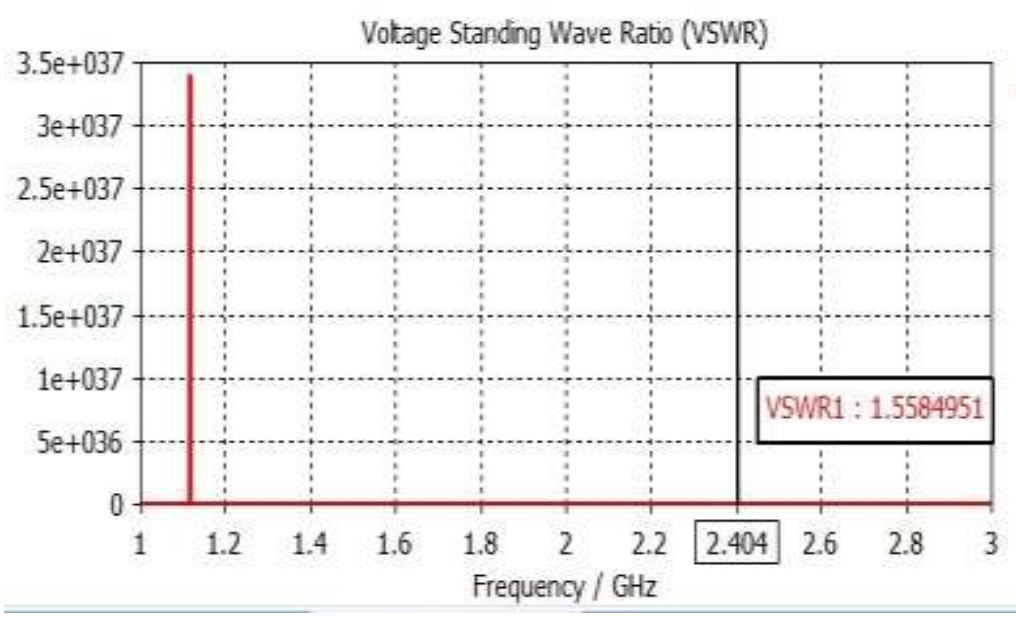

Fig. 4 VSWR of Conventional M.P.A.

Farfield Gain Abs (Phi $=90)$

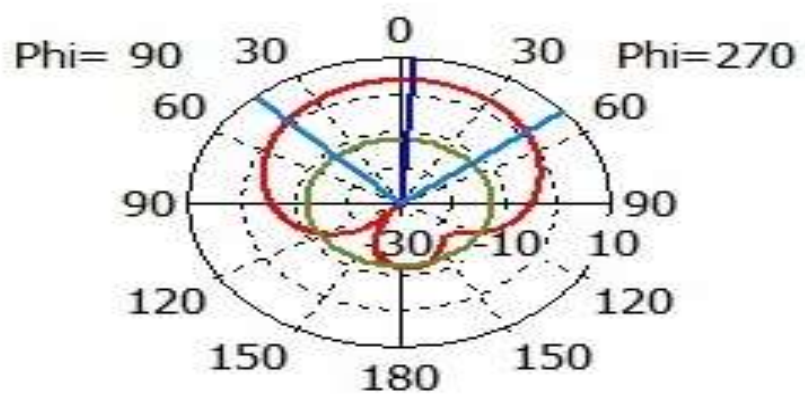

Theta / Degree vs. dB

Fig. 5 2D radiation pattern of Conventional M.P.A. 


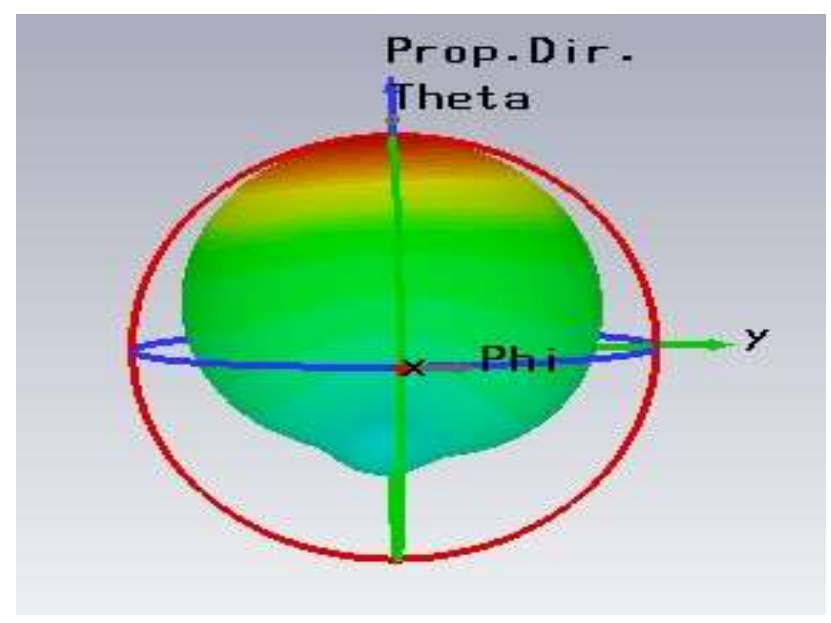

Fig. 63 D radiation pattern of Conventional M.P.A.

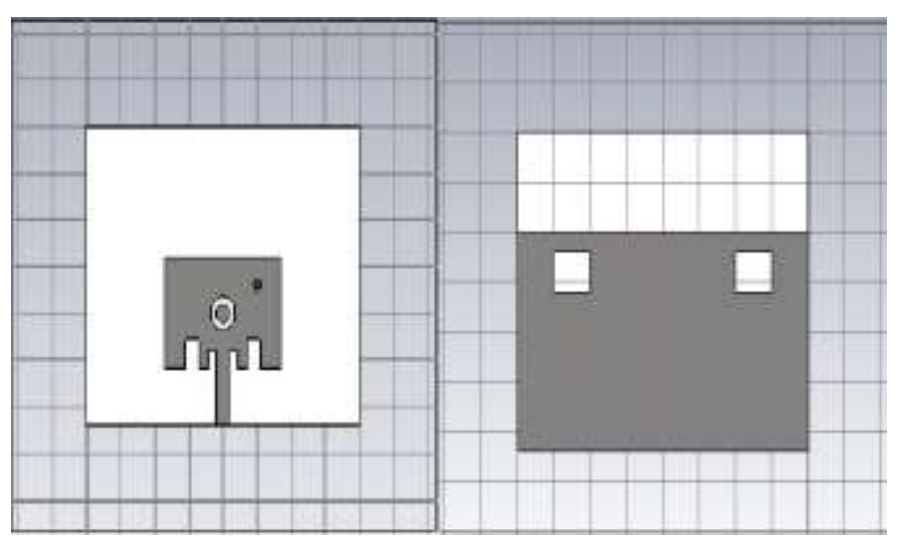

Fig. 7 a) E Shaped Microstrip antenna b) Partial Ground Plane

Table I. Antenna Design Parameters

\begin{tabular}{|c|c|}
\hline Antenna parameters & Value \\
\hline $\mathrm{W}$ & 17.2 \\
\hline $\mathrm{L}$ & 12 \\
\hline $\mathrm{Fi}$ & 8.1 \\
\hline $\mathrm{Wf}$ & 1 \\
\hline $\mathrm{Gpf}$ & 1.8 \\
\hline $\mathrm{Lg}$ & 32 \\
\hline $\mathrm{Wg}$ & 40 \\
\hline $\mathrm{Ht}$ & 0.035 \\
\hline $\mathrm{Hs}$ & 1.6 \\
\hline
\end{tabular}

CST software is preferred for the design and simulation of this E shaped antenna. Table 1 exhibit the design parameters of the antenna. Figure 1 shows E shaped microstrip patch antenna with partial ground. 


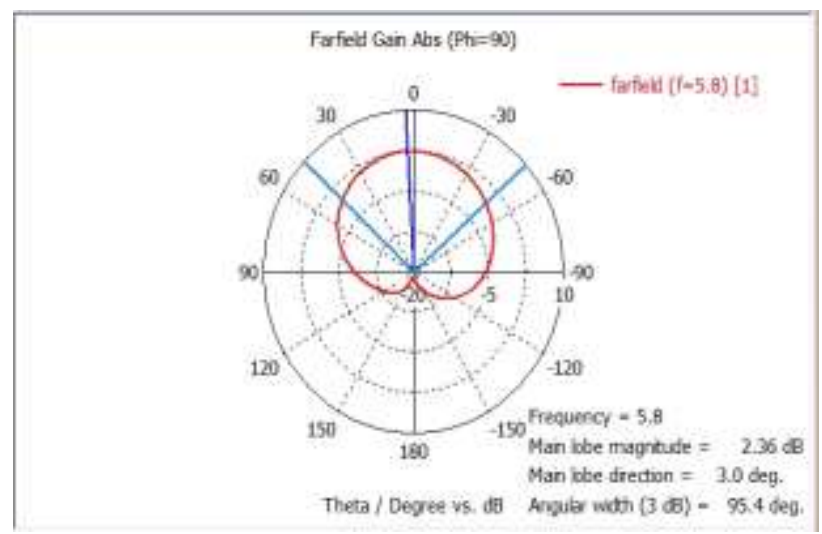

Fig. 8 Gain

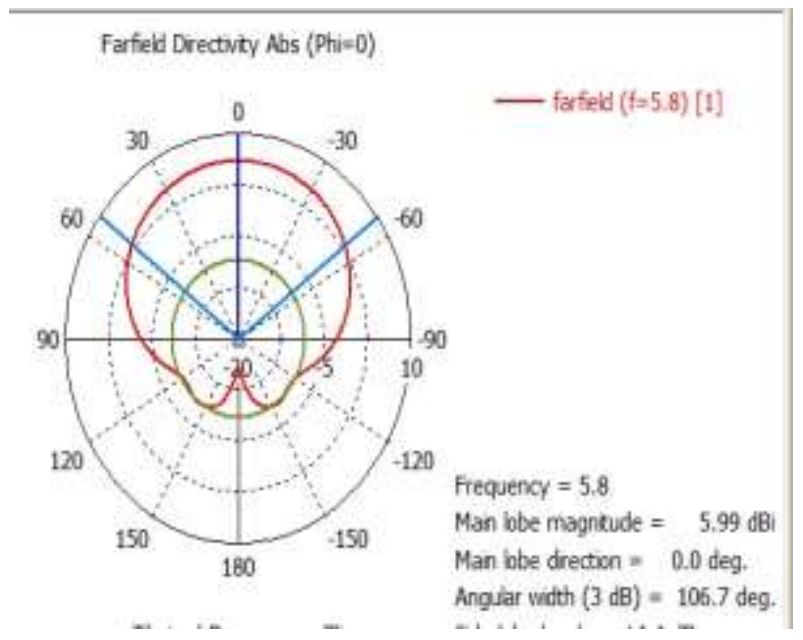

Fig. 9 Directivity

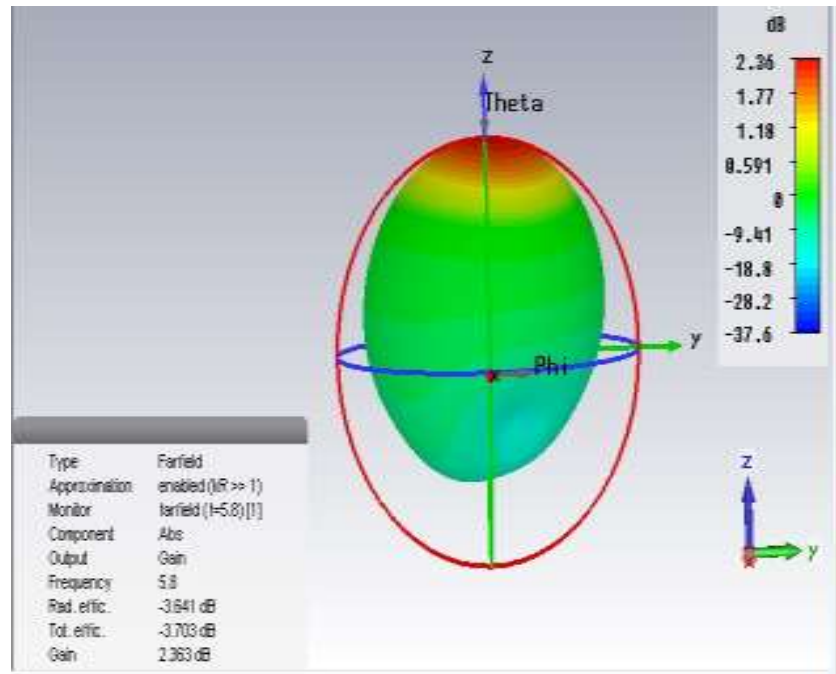

Fig. 10 Gain 


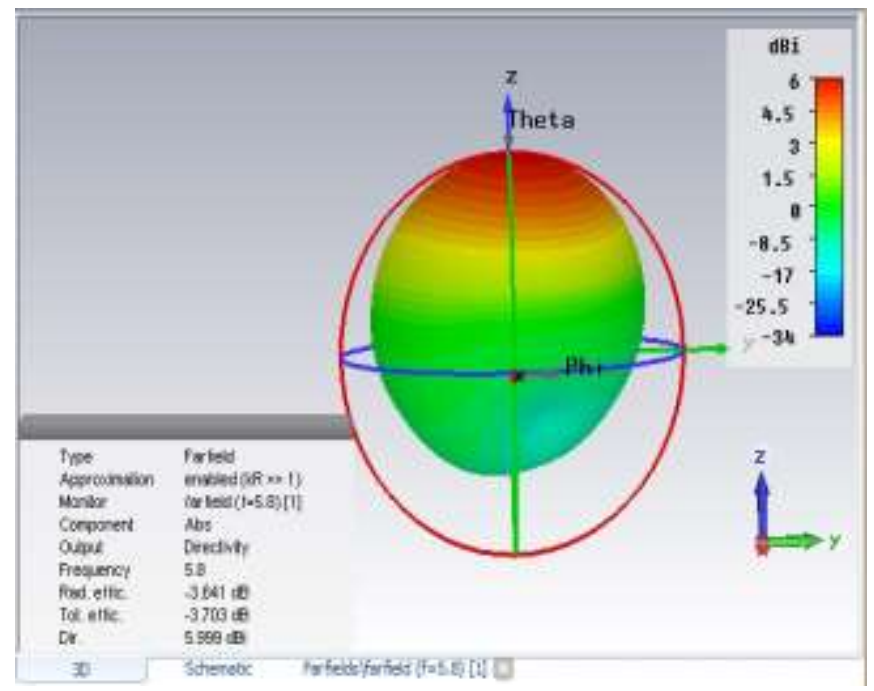

Fig. 11 Directivity

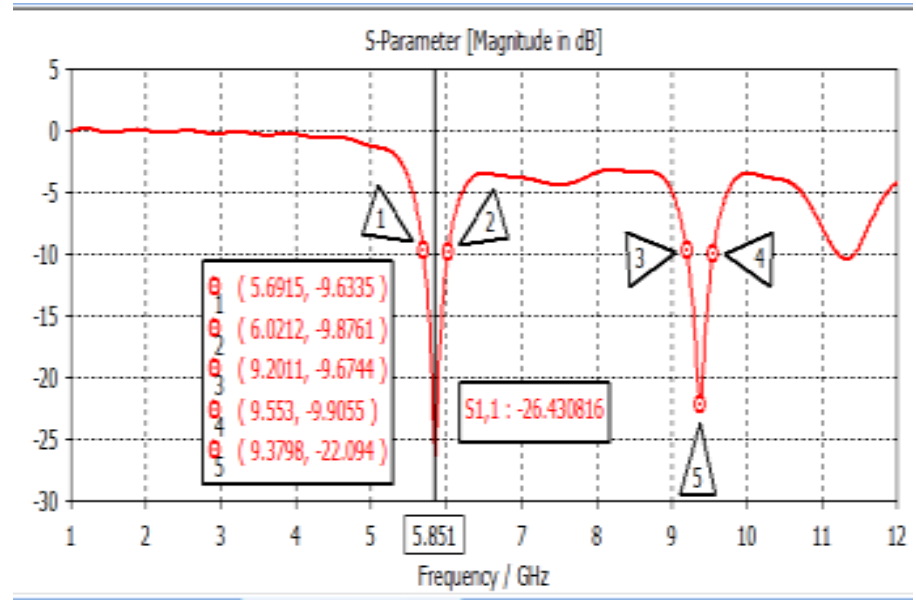

Fig. 12 Return Loss S11

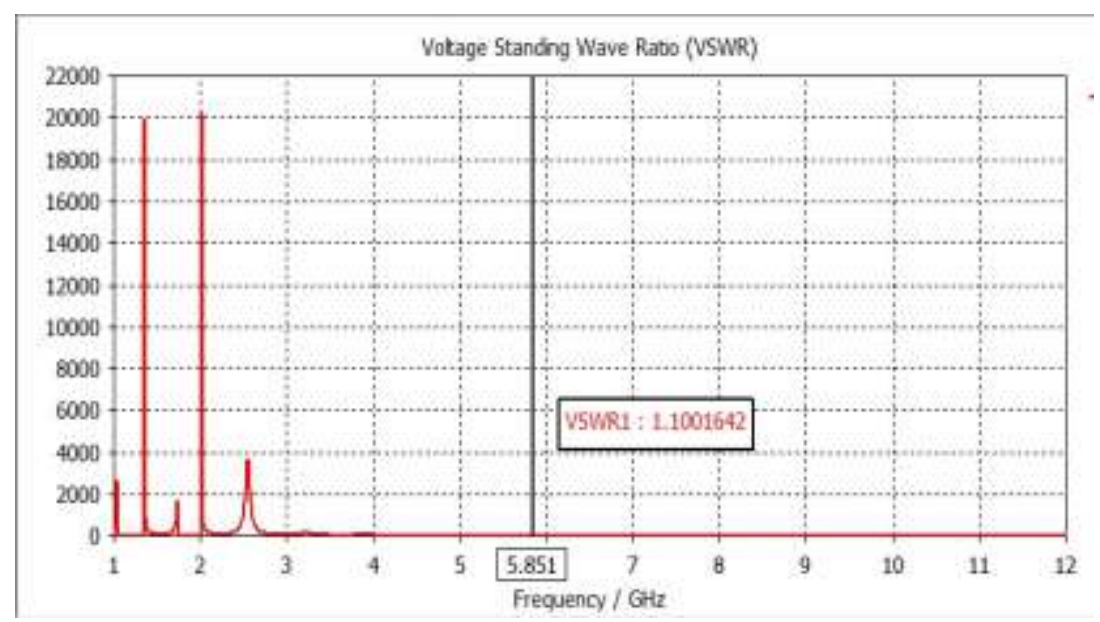

Fig. 13 VSWR

Figure 14 shows the antenna design with three parasitic patches and ground palne alterations. One circular slot inserted into the ground plane. The ground plane is not symmetric. In this design one rectangular slot is replaced by circular slot. In first design 
both the rectangular slots are placed in horizontal fashion. In second design the slots arrangement have been changed. Now the slots are vertically placed. The upper parasitic patch is wider than the remaining two patches. The remaining two patches are longer than the It has been observed that after the DGS, antenna bandwidth intensify a lot up to 1100 $\mathrm{MHz}$ and $1430 \mathrm{MHz}$ for S band \& $\mathrm{X}$ band.
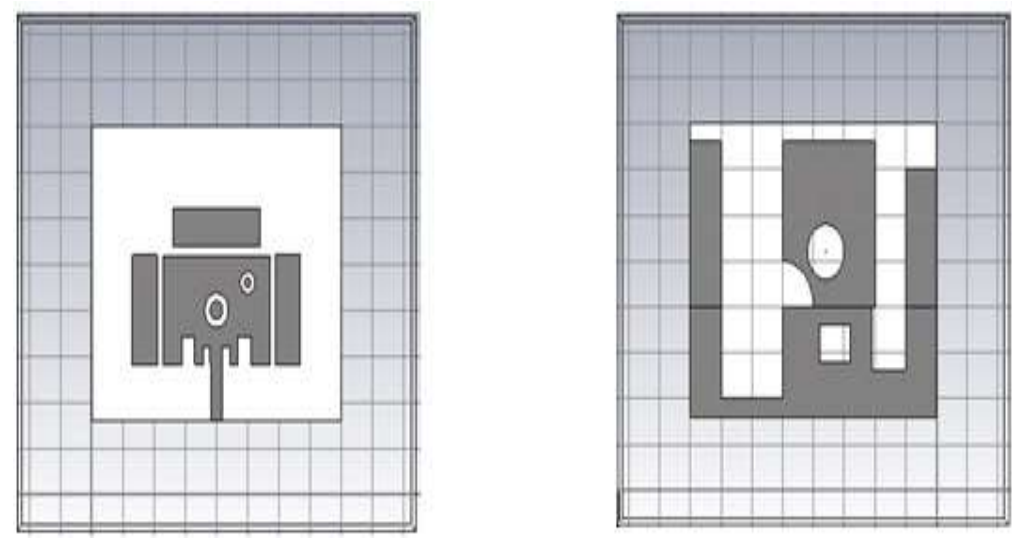

Fig. 14 a) E Shaped Patch antenna with parasitic patches b) Defected ground plane

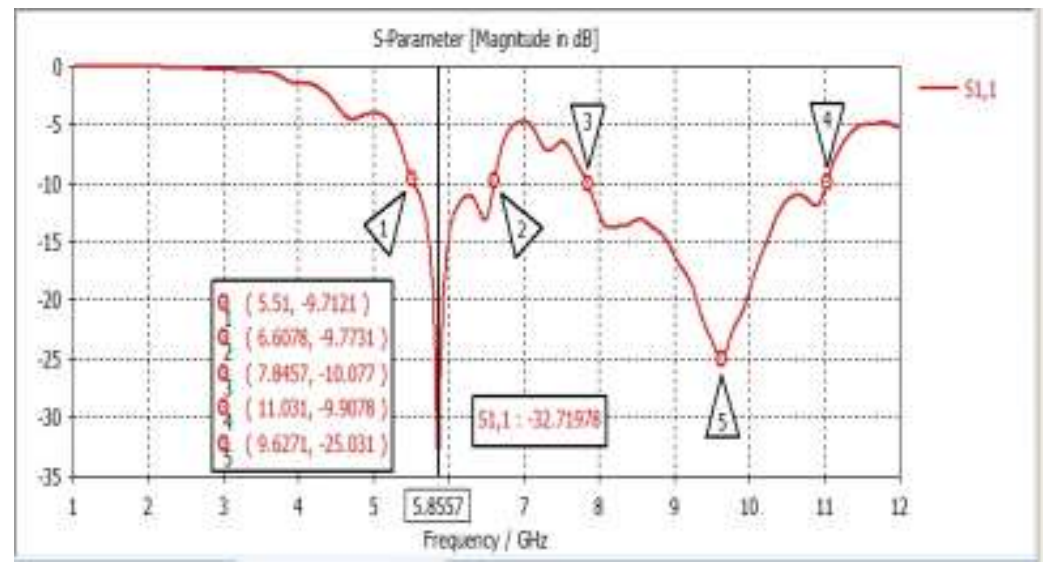

Fig. 15 S11 of E shape Patch Antenna with parasitic patches

Table II. Output Characteristics of Antennas /Comparison

\begin{tabular}{|l|l|l|l|l|}
\hline Parameters & \multicolumn{2}{|l|}{$\begin{array}{l}\text { E shape Antenna without parasitic } \\
\text { Patches }\end{array}$} & \multicolumn{2}{|l|}{$\begin{array}{l}\text { E shape Antenna with } \\
\text { parasitic Patches }\end{array}$} \\
\hline $\begin{array}{l}\text { Operating frequency in } \\
\text { GHz }\end{array}$ & \multicolumn{1}{|c|}{5.8} & 9.3 & 5.8 & 9.6 \\
\hline Input Impedance & $50.14 \mathrm{ohm}$ & $50.14 \mathrm{ohm}$ & $50.14 \mathrm{ohm}$ & $50.14 \mathrm{ohm}$ \\
\hline Return Loss & $-26.43 \mathrm{~dB}$ & $-22.09 \mathrm{~dB}$ & $-32.7 \mathrm{~dB}$ & $-25.03 \mathrm{~dB}$ \\
\hline VSWR & 1.1 & 1.1 & 1.04 & 1.1 \\
\hline Gain & $2.368 \mathrm{~dB}$ & $2.368 \mathrm{~dB}$ & $3.61 \mathrm{~dB}$ & $3.61 \mathrm{~dB}$ \\
\hline Directivity & $5.99 \mathrm{~dB}$ & $5.99 \mathrm{~dB}$ & $6.171 \mathrm{~dB}$ & $6.171 \mathrm{~dB}$ \\
\hline SLL & -- & -- & $-5.4 \mathrm{~dB}$ & $-5.4 \mathrm{~dB}$ \\
\hline Bandwidth & $400 \mathrm{MHz}$ & $300 \mathrm{MHz}$ & $1100 \mathrm{MHz}$ & $1430 \mathrm{MHz}$ \\
\hline
\end{tabular}




\section{CONCLUSION}

It has been concluded that after the incorporation of DGS technique into the structure, bandwidth of an antenna improves remarkably. In the first design slots have been inserted in the ground plane and also partial ground structure has been incorporated. Gain and directivity also improves to some extent. Table I shows the design parameters of an antenna. Table II shows the comparison of both the antennas with and without parasitic patches. We get bandwidth of $400 \mathrm{MHz}$ and $300 \mathrm{MHz}$ at $5.8 \mathrm{GHz}$ and $9.3 \mathrm{GHz}$. Return loss is upto $-26.43 \mathrm{~dB}$ and $-22.09 \mathrm{~dB}$ for this antenna. VSWR has been attained upto 1.1. The proposed design reported a dual band with resonating frequencies at $5.8 \mathrm{GHz}$ and 9.3 $\mathrm{GHz}$ having remarkable bandwidth about $1100 \mathrm{MHz}$ and $1430 \mathrm{MHz}$ respectively. After incorporating parasitic patches into the structure, the return loss was improved upto -32.7 $\mathrm{dB}$ and VSWR upto 1 . Gain and directivity also get increased by $1 \mathrm{~dB}$ after the inclusion of parasitic patches. It has been concluded that for the antenna with parasitic patches, bandwidth increases by a large amount. Bandwidth get increased by $700 \mathrm{MHz}$ and $1.13 \mathrm{GHz}$ at the resonance frequency of $5.8 \mathrm{GHz}$ and $9.3 \mathrm{GHz}$. This is the novelty of the paper. It has been observed that $3 \mathrm{~dB}$ bandwidth increases after incorporating DGS and notches into the patch. This antenna covers both $\mathrm{S} \& \mathrm{X}$ band simultaneously. The return loss observed for this antenna was $-32.7 \mathrm{~dB}$ at $5.8 \mathrm{GHz}$ and $-25.03 \mathrm{~dB}$ at $9.3 \mathrm{GHz}$. Besides we have investigated VSWR which was reported to be 1 .

\section{REFERENCES}

[1] Tanuj Garg, "Hexagonal Shaped Slotted Microstrip Patch Antenna", International Journal of Engineering Science and Computing, vol 6, Issue No.3, ISSN: 2321-3361.

[2] Puneet Khanna, Kshitij Shinghal, Arun Kumar, "Multi Band Annular Ring Microstrip Antenna with Defected Ground Structure for Wireless Communication", International Journal of Computer Applications, Vol.135, Issue No. 2, ISSN: 0975-8887, February (2016), pp-19-25

[3] Ken Paramayudha, Arief Budi SAntiko, Yuyu Wahyu, Aidil Filtriadi, Heroe Wijanto, "Design and Realization of Circular patch Antenna for S-band Coastal Radar", IEEE International conference on Radar, Antenna,Microwave,Electronics and Telecommunication, (2016), pp-115-118.

[4] Amandeep Kaur Sidhu, Jagtar Singh Sivia, "Microstrip Rectangular Patch Antenna for S and X Band Applications", IEEE WiSPNET (2016) conference, pp-248-251.

[5] Babulal Sharma, Girish Parmar, Mithilesh Kumar, "Design frequency Reconfigurable Microstrip Patch Antenna for S Band Application", IEEE conference (2015).

[6] Shipra Singh, Rahul Kumar Verma, "Rectangular Grid Type Patch Antenna for S band and X band applications", IEEE International conference on Signal Processing and Integrated Networks, (2017), pp267-269.

[7] Rihana Parveen, Mohd Abdulla, "Broadband compact antenna for S band and C band application", International Journal of Computer Application, ISSN: 0975-8887, Vol. 160, Issue No.8, Feb (2017), pp5-9.

[8] K. Wanjari, S. Dhruv, R. Deshmukh, P. Raut, C. Dhongade, Kanchan Wagh, "Design \& Analysis of Inset Fed Microstrip Patch Antenna for Wireless Communication", Advanced Science \& Technology Letters, Vol. 147, (2017), pp-296-304, ISSN: 2287-1233.

[9] Daiki Kawase, Kunio Sakakibara, Kazuyuki Seo, Nobuyoshi Kikuna, Hiroshi Hirayama, "Design of Microstip antennas fed by four Microstrip-port wave guide transition with slot Radiators", Proceedings of ISAP 2012, Nayoya, Japan ( 2012).

[10] Wen-Qin Wang, "Overview of frequency diverse array in Radar \& navigation application", IET Radar, Sonar \& Navigation,Vol 10, Issue 6, (2016) Pp-1001-1012, ISSN:1751-8784.

[11] J. Ehmouda, Z. Briqech \& A. Amer, "Steered Microstrip Phased Array Antennas", World Academy of Science, Engineering \& Technology, 49, (2009).

[12] C. A. Balanis, "Antenna Theory", $3^{\text {rd }}$ Edition, John Wiley, New York, (2005).

[13] Ramesh Garg, Prakasah Bhartia, Inder Bahl, "Microstrip Antenna Design Handbook", Artech House, Boston London, (2001).

[14] Girish Kumar, K. P. Ray, Broadband Microstrip Antennas, Artech House.

[15] Kanchan H. Wagh, "Microstrip Array Antenna and Beamforming Algorithm for Phased Array Radar", Journal of Advanced Research in Education \& Technology, Vol.2, Issue July-Sept. (2015), pp. 148-151, ISSN: 2394-2975.

[16] Kanchan H. Wagh, Dr. S. S. Shriramwar, "Design of Microstrip Antenna Array for RADAR Application: A Review", International journal of modern electronics and communication engineering (IJMECE) March, (2019), ISSN: 2321-2152, volume No.-7, Issue No.-2. 
[17] Kanchan H. Wagh, Dr. S. S. Shriramwar, "Gain and Bandwidth Enhancement of Antenna Array for S and C Band Application", International journal of recent technology and engineering, ISSN: 2277-3878 (Online), volume-7 Issue-6, March (2019), pp. 1239-1241.

[18] Kanchan Wagh, S. S. Shriramwar, "Miniaturization and Gain Enhancement of Array Antenna for Dual Band RADAR System", IEEE Indian Conference on Antenna and Propagation, $16^{\text {th }}$ Dec (2018), pp. 14.

[19] Kanchan H. Wagh, "A review on fractal antennas for wireless communication”, International Journal of Research in Electronics and Computing Engineering, Vol. 3, Issue 2, May (2015), pp. 37-41.

[20] Kanchan H. Wagh, "An Overview of Fractal Antenna for Wireless Communication”, International Journal on Recent and Innovation Trends in Computing \& Communication, Vol. 3, Issue 2, (2015), pp124-129, ISSN: 2321-8169. 